\title{
Reuna
}

\section{TEORIA DAS RESTRIÇÕES TRATADA SOB A ÉGIDE DAS ROTINAS E DA ESTRUTURAÇÃO SOCIAL}

\author{
THEORY OF CONSTRAINT ENCAPSULETED IN ROUTINES AND SOCIAL \\ STRUCTURATION STUDIES
}

http://dx.doi.org/10.21714/2179-8834/2017v22n1p21-40

\author{
Francisco Oliveira Machado \\ Universidade Federal de Pernambuco, Brasil. \\ Endereço: Rodovia BR 104, Km 61, Sítio Jurití, CEP 55002-970 - Caruaru, Pernambuco - Brasil \\ Fone:+55 (81) 21267773 \\ Email: fmachado@ufpe.br - Lattes: http://lattes.cnpq.br/0225303902969855
}

Marcos André Mendes Primo

Universidade Federal de Pernambuco, Brasil.

Endereço: Av. Professor Moraes Rego, 1235, Cidade Universitária, CEP 50670-901, Recife, Pernambuco Brasil / Fone: +55(81)3269-0539

Email: marcosprimo0@gmail.com - Lattes: http://lattes.cnpq.br/080140252118301:8

Submissão: 25 Jan. 2016 Publicação: 31 Mar. 2017. Sistema de avaliação: Double blind review. Centro Universitário UNA, Belo Horizonte - MG, Brasil. Editor geral Prof. Dr. Mário Teixeira Reis Neto

Este artigo encontra-se disponível no endereço eletrônico:

http://revistas.una.br/index.php/reuna/article/view/774

http://dx.doi.org/10.21714/2179-8834/2017v22n1p21-40

\section{Resumo}

A Teoria das Restrições é consolidada e tratada em estudos de Produção e Operações, contudo não foi evidenciada a possibilidade de se integrar tal teoria com a Teoria da Estruturação Social. Dessa forma, o presente trabalho teórico conceitual tem por intuito/objetivo trazer à discussão a Teoria das Restrições, no que tange à sua recomendação sobre o processo de enfoque em cinco etapas, moldando-a aos preceitos da Estruturação Social, a qual tem por limites dois reinos: (1) o institucional e o (2) das ações. No interior destes dois, inserem-se as rotinas como determinantes ao gerenciamento de recursos. Espera-se que as proposições geradas possam ser aprofundadas em estudos futuros.

Palavras-Chave: Rotinas; Regras; Recursos; Teoria das Restrições; Teoria da Estruturação Social. 


\begin{abstract}
The Theory of Constraints is consolidated in Production and Operation Management studies. However, inside academic literature, this theory is not associated with Social Structuration Theory. This conceptual paper aims to discuss the Theory of Constraints, especially with its five steps approach, under the Social Structurarion perspective. The Social Structuration is delimited for two borders: (1) the institutional realm; and (2) the actions realm. Routines are placed in the middle of its limits, and they determine the resources management. We develop some propositions that hopefully can be further studied.
\end{abstract}

Key-Words: Routines; Rules; Resources; Theory of Constraints; Social Structuration Theory

\title{
1. Introdução
}

A organização é um sistema produtivo que interage com o meio, para dele obter recursos, processá-los e entregar seus produtos finais a um mercado que atribua valor na transação de troca envolvida (SLACK; CHAMBERS; JOHNSTON, 2009). Com tal finalidade, toda e qualquer organização precisa ter um mecanismo integrador que coordene as ações tomadas pelas pessoas (MINTZBERG, 2003), as quais, com o passar do tempo, passam a ser um padrão de interação recorrente adotado pelas pessoas, que se materializam nas rotinas organizacionais (BECKER, 2004; 2005a; 2005b).

As rotinas são a genética da organização (NELSON; WINTER, 2005) e se desenvolvem tendo por base as regras (GROTE et al., 2009) criadas para registrar e codificar, normalmente em artefatos (PENTLAND; FELDMAN, 2008), o que deve ser feito e evidenciado no comportamento produtivo das pessoas, nas suas rotinas na prática (GROTEet al., 2009). "As regras refletem o comportamento maximizador por parte das firmas" (NELSON; WINTER, 2005, p. 29).

Para Feldman (2000) rotinas organizacionais são o padrão repetitivo, que todas e quaisquer organizações possuem e que podem vir a ser modificadas quando há a ativação de um fluxo circular que se inicia com (1) ideias, que são materializadas em (2) planos, com os quais buscam-se (3) ações a fazer, nas quais as (4) saídas são seu resultado esperado, ou não. Esse fluxo foi trabalhado, mais adiante no tempo, pela autora, que chegou a desenvolver um círculo da criação de recursos (FELDMAN, 2004).

Feldman (2004) alega que recursos permitem que pessoas atuem nas organizações em conformidade com esquemas de como proceder em determinadas situações da vida rotineira. Nesse proceder, diante das diversas possibilidades de ações, na relação de esquemas de ação e recursos que se tem disponibilizados, como conhecimento, dinheiro e tempo, é que a possibilidade de criar novos recursos é desenvolvida (FELDMAN, 2004). Ou seja, pode-se inferir que as rotinas desenvolvem alternativas à organização para lidar com situações adversas, mudanças ambientais e restrições na ação ante o planejado. 
No entanto, há a distinção entre ativação e utilização de recursos, segundo Goldratt e Cox (2014). O primeiro conceito se relaciona ao passar de um recurso por entre uma máquina, por exemplo. O segundo, da utilização, associa-se à contribuição que um recurso possui em termos de cumprir um objetivo organizacional. Goldratt e Cox (2014) focam-se na utilização dos recursos e passam a entender como pode ser otimizado o processo produtivo, em termos de os recursos serem utilizados de forma mais eficiente, ao cumprimento do objetivo organizacional. Busca-se, então, com a implementação das cinco etapas, a criação de um padrão de interação recorrente a ser adotado pelas pessoas, caracterizando, assim, a consolidação desta rotina organizacional (BECKER, 2004; 2005a; 2005b)

Partindo do alicerçamento conceitual pautado nas rotinas, desenvolveu-se o presente trabalho teórico conceitual, com o intuito/objetivo de trazer à discussão a Teoria das Restrições no cerne dos estudos das rotinas organizacionais. Mais especificamente, contrapondo as recomendações sobre o processo de enfoque em cinco etapas (CSILLAG, 1991; GOLDRATT; COX, 2014), com o olhar da modelagem proposta por Burns e Scapens (2000) no trato das rotinas.

Tais rotinas representam um padrão de interação recorrente das pessoas (BECKER, 2004; 2005a; 2005b), alicerçadas em regras (GROTEet al., 2009) e que, quando em fluxo circular, servem ao criar novos recursos para lidar com situações novas, inserindo, assim, as adversas (FELDMAN, 2004). Ou seja, os esquemas desenvolvidos por Feldman (2004) para a ativação de recursos se aproximando da discussão das cinco etapas.

Dessa forma, o trabalho inicia-se por apresentar conceitos sobre a teoria das restrições como um norte de estudo que se desenvolveu sob a égide das rotinas. Em seguida, de forma a direcionar as análises que foram proferidas.

\section{Teoria das Restrições: Conceitos e noções envolvidos sob a égide das rotinas}

A Teoria das Restrições foi desenvolvida tendo por intuito a integração da organização como um sistema, de vê-la como um todo integrado, no intuito do estabelecimento de uma maior lucratividade, a meta da empresa. O intuito desta teoria é ter por enfoque a restrição do sistema produtivo em sua totalidade (GOLDRATT; COX 2014). Isso impede que a produtividade do sistema seja de forma (1) física, associada a materiais, capacidade de produção, logística e mercado; ou de forma (2) não física, que é ligada a aspectos gerenciais e de comportamentos, tal quais normas, procedimentos e práticas (MARQUES; CIA, 1998). Considera-se, portanto, a integração da fabricação como um "sistema integrado", na qual a coordenação e cooperação entre as partes devam ser enfocadas (CSILLAG, 1991, p. 62).

Como foi já mencionado na introdução do trabalho, pode-se dizer que a organização é um "emaranhado" de rotinas, que são importantes ao desenvolvimento de qualquer atividade, seja esta de cunho operacional, tático ou, até mesmo, estratégico. As rotinas, em seu conjunto integrado, formam as capacidades da firma, especialmente as de inovação e melhoria (PENG; SCHROEDER; SHAH, 2008). Mais ainda, alicerçados em Mintzberg (2003), pode-se alegar que é necessário às 
organizações possuírem mecanismos de coordenação, para estabelecimento de elos entre as partes que a compõem. Se acepção de elo for semelhante à de integrar, de unir, infere-se que as rotinas são o "gene" integrador, que se alicerça nos mapas mentais e habilidades das pessoas (NELSON; WINTER, 2005).

A genética de Nelson e Winter (2005, p. 26-29) é relacionada aos processos pelos quais as características organizacionais, particularmente, de crescimento e de lucratividade perpassam e são transmitidas ao longo do tempo. Trata-se da possibilidade de encarar mudanças como algo que evolui e emerge por meio de processos dinâmicos, de uma dada realidade conhecida, de um padrão, de regras operacionais estabelecidas. Esta mudança de cunho evolutivo por si só remete à questão do "mundo do ganho" da teoria das restrições, nas quais a possibilidade de encarar quais pontos são centrais e que influenciam o desempenho total do sistema em seu crescimento (CSILLAG, 1991; GOLDRATT; COX, 2014).

A partir do entendimento padronizado dos processos, a dinâmica da gestão operacional volta-se a entender como melhorar a eficiência, eficácia e efetividade da aplicação de recursos e esforços organizacionais em cima dos processos que estão interligados. Se há interligação, então, pode-se fazer a analogia com a corrente de estudos na qual o elo mais fraco impacta o desenvolvimento da produção em que todos os elos estão interligados entre si. O elo mais fraco é a restrição na qual esta corrente teórica se debruça a fim de que a organização atinja melhor seus objetivos (GOLDRATT; COX, 2014).

Portanto, as restrições podem ser qualquer aspecto que limite o sistema, em sua tentativa de conseguir maior desempenho (CSILLAG, 1991). Associando-se ao que já foi dito, as restrições podem ocorrer na forma física e não física. De acordo com Marques e Cia (1998), as restrições de forma física são de mais fácil detecção, o que remete à Teoria da Visão Baseada em Recursos - RBV.

Considerando a RBV, os recursos, sejam estes: os capitais físico, humano e/ou organizacional (BARNEY, 1991), podem ser base para o êxito da organização, como também serem restritivos à sua competitividade. Tal analogia remete à possibilidade de ligação teórica quanto ao visualizar da RBV e as restrições, especialmente, quando da modelagem do fluxo circular de Feldman (2004) explanada na introdução do artigo e posto a seguir. Esta autora defende que as ações tomadas pelas pessoas, delimitadas pelas rotinas organizacionais, criam recursos que habilitamnasa desenvolverem esquemas de ação e de criação de mais recursos. 


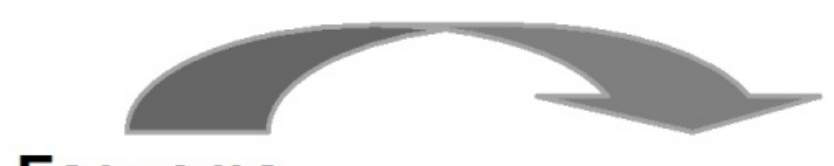

Esquema

\section{Ações}

\section{Recursos}

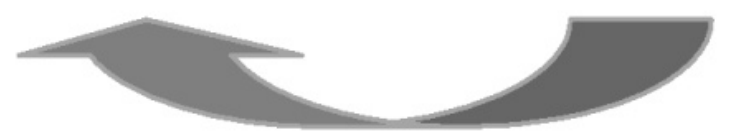

Figura 1 - Ciclo de Recursos

Fonte: adaptado de Feldman (2004, p. 296).

Contudo, nas restrições de ordem não física (MARQUES; CIA, 1998), também chamadas de comportamentais, residem melhores possibilidades de se trabalhar com a teoria da restrição conjuntamente com a estruturação social de Giddens (1984).

De acordo com Marques e Cia (1998, p. 36), a Teoria das Restrições pode ser dividida em três campos distintos: (1) conjunto de ferramentas, destinadas para solucionar problemas gerencias, que são empregadas de modo a responder lógica e sistematicamente às três questões essenciais de qualquer processo de melhoria de resultados: "o que mudar", "para o que mudar" e "como causar a mudança"; (2) subconjunto de ferramentas de gerenciamento do dia a dia, usado para aperfeiçoar as habilidades gerenciais em pontos-chaves, como comunicação e realização; e (3) fruto de soluções inovadoras criadas a partir da aplicação dos processos de raciocínio, do tópico anterior.

Considerando o primeiro campo apontado por Marques e Cia (1998), pode-se concluir que o enfoque da mudança é tratado de forma central na proposta desse trabalho. A mudança, na condição de fenômeno, é estudada em diversas áreas do conhecimento. Dentre as teorias possíveis parase abordar o tema, faz-se presente na Teoria da Estruturação, com a qual tem-se Giddens (1984) como autor de destaque.

\section{Teoria da Estruturação Social e as Rotinas Organizacionais}

Sobre a obra de Giddens (1984), ressaltam-se os pressupostos de que sua teoria de estruturação social é fruto da dualidade entre o agente e a instituição. Giddens (1984, p. xvii) alega que a "teoria social" se interessa por entender a natureza da ação humana e do agir, com a qual a interação pode ser concebida e sua relação com instituições possui conotação de práticas na análise social. A teoria social se interessa por compreender o processo concreto da vida social, logo é constituída de esquemas conceituais. Estes esquemas norteiam a forma como as pessoas podem vir a agir sobre as rotinas e regras, sendo até mesmo confundidas com estas. 
Regras e rotinas estando postas no centro dos reinos institucional e das ações, com base em Burns e Scapens (2000).

Para o entendimento da teoria da estruturação, segundo Giddens (1984), faz-se necessária a compreensão de três conceitos: (1) estrutura; (2) sistema; e (3) dualidade na estrutura. A estrutura pode ser compreendida como externa à ação humana, como recurso que restringe esta atuação, independentemente da constituição do sujeito. A estrutura é tratada, no sentido mais elementar, com associação a regras e recursos, na qual podem ser discutidas como procedimentos metodológicos de interação (GIDDENS, 1984).

Sobre a dualidade da estrutura, Giddens (1984, p. 25) apresenta uma síntese do que vem a ser: (1) estruturas; (2) sistemas; e (3) estruturação. Estruturas são regras e recursos, o conjunto de relação de transformação, organizados como propriedade de sistema social. Sistema seria a reprodução de relação entre atores e coletividade, organizada como prática social regular. Estruturação são as condições de governar a continuidade ou transmutação da estrutura, portanto, a reprodução do sistema social.

Giddens (1984, p. 30-31) distingue três dimensões estruturais do sistema social: (1) significação, na qual o domínio teórico é a teoria da codificação, e o controle institucional é por meio dos símbolos e modos de discurso; (2) dominação, pois o domínio é a teoria da autorização e alocação de recursos, reciprocamente, oriundos da política e economia institucional, como formas de controle; e (3) legitimação, na qual o domínio teórico é da regulamentação normativa, e o controle institucional é por meio legal.

Associando a Teoria das Restrições com a Estruturação Social, o paralelo ocorre em termos de haver a dimensão estrutural de domínio com "os grupos de poder" que interferem no estabelecimento da meta da organização (CSILLAG, 1991, p. 65). Cada grupo, assim como o isomorfismo normativo de DiMaggio e Powell (1983), vem a estabelecer o que deve ser feito e como deve ser feito, de acordo com seus interesses. Começa, então, a ser traçado um paralelo da teoria institucional e da estruturação social com a das restrições, em termos de que as "entidades" externas, doravante chamadas de grupos de poder, interferem no "mundo do ganho" das organizações "institucionalmente".

Sobre as três dimensões, o paralelo com os três pilares da abordagem institucional de Scott (1995) pode ser feito, assim tem-se que a dimensão estrutural (1) significação se associa com o pilar cognitivo; (2) dominação com o pilar normativo; e (3) legitimação com o regulador. Nesse sentido, é oportuno lembrar que cada um destes pilares possui associação com os mecanismos institucionais de DiMaggio e Powell (1983) respectivamente: mimético, normativo e coercitivo.

Portanto, o trabalho de Giddens, particularmente a obra de 1984, consiste em pôr a agência, a reflexão do agente e suas ações com enfoque para se mudar instituições (WHITTINGTON, 1992). Nesse sentido, Whittington (1992) abre a perspectiva para que, se há conhecimento e reflexão, deve haver o papel do agente no desenvolvimento da estruturação social. Por isso, o maior legado da estruturação social de Giddens é ver o entendimento da sociedade, em termos de existir o reino institucional sendo desenvolvido em paralelo com o das ações das pessoas. Estas pessoas agindo para modificar regras e rotinas ao longo do tempo, e esta mudança sendo incorporada nas instituições (BARLEY; TOLBERT, 1997).

REUNA, Belo Horizonte - MG, Brasil, v.2Z, n.I, p.Z1-4D, Jan. - Mar. 2017 - ISSN 2179-8834 


\section{A Agência na Estruturação Social e nas Rotinas Organizacionais}

Feldman (2000), baseada nas mudanças de rotina, propôs um modelo performativo de rotinas organizacionais, no qual sugere que a dinâmica interna das rotinas promove mudanças contínuas. A autora alega que a mudança ocorre como resultado de reflexão e reação de indivíduos, que estão envolvidos na rotina, bem como de sua própria interação. O modelo enfatiza que agência é elemento importante das rotinas e explica como elas mudam (FELDMAN, 2000, p. 620). Rotinas são importantes para serem estudadas, pois nelas são performadas as diversas atividades da organização, por meio do trabalho de pessoas e de máquinas.

Feldman (2000) apresenta as rotinas performativas, o cerne de seu modelo desenvolvido, e as ostensivas. Sobre as ostensivas, a autora declara que elas devem ser desprovidas de pensamento ativo. Contudo, "rotinas perfomadas por pessoas nas organizações inevitavelmente envolvem um amplo espectro de ações, comportamentos, pensamentos e sentimentos" (FELDMAN, 2000, p. 622).

No aspecto performativo, a agência é inserida. Como trabalho importante à discussão do que vem a ser agência, Emirbayer e Mische (1998) a contextualiza como processo temporariamente embebido no engajamento social. Neste último, o passado serve de fonte de informação, na interação ou no hábito, mas que orienta para o futuro, como capacidade de se pensar, projetar possibilidades alternativas. Passado e futuro se unem no momento presente, quando contingências destes dois planos são postas em prática e em processo de atual avaliação. Ou seja, a agência molda a ação social (EMIRBAYER; MISCHE, 1998).

No entanto, Emirbayer e Mische (1998) distinguem duas formas de se ver as ações. Estas podem ser instrumentais, baseadas em técnicas e tecnologias, e normativas, alicerçadas em normas e regras. Estas duas possibilidades vão delimitar e reger a forma como as pessoas refletem acerca do momento presente. Portanto, para Emirbayer e Mische (1998), a agência e sua teoria são compostas de três elementos constitutivos: (1) interacional, referente ao passado e à capacidade dos atores de ter as suas práticas relacionadas com o padrão passado de ação e pensamento, que são rotineiramente incorporadas e servem para conferir identidade estável, interação e institucionalização; (2) projetivo, referente ao futuro em suas possíveis trajetórias de ação, que são reconfiguradas pelos atores, com base em seus medos, esperanças e desejos de futuro; e (3) avaliativo prático, o qual refere-se ao presente, às práticas e às normas que julgam e determinam as possíveis trajetórias de ação.

Estes indivíduos, os agentes para Emirbayer e Mische (1998), desenvolvem três papéis ante rotinas e regras, segundo Weichbrodt e Grote (2010): o fazedor, o seguidor e o supervisor de regras. Quem faz a regra detém, de certa forma, poder. Outra questão interessante quanto ao fazedor de regras é que sua figura surge em situações em que haja ambiguidade, e não congruência de objetivos. O intuito do estabelecimento de regras e de sistemas burocráticos é de se ter um sistema de controle. Por isso que muitas organizações optam por abolir, em determinadas 
situações, estes mecanismos controladores, segundo Weichbrodt e Grote (2010). Os desvios das regras servem de oportunidades para aprender.

Quem fica encarregado de supervisionar regras também sofre influência da situação. Porém, o que é importante ressaltar, com base em Weichbrodt e Grote (2010) acerca de quem supervisiona a regra, é o poder que esta entidade possui em termos de controlar a aderência sobre a regra em questão. Portanto, quem desenvolve este papel deve se atentar ao fato de que pode haver situações em que pessoas não seguem regras, devido ao fato de que elas podem não ser mais alinhadas ao comportamento necessário ao desenvolvimento de rotinas.

Seguir a regra, para aqueles que as obedecem, em consonância com Weichbrodt e Grote (2010), é cumpri-las a fim de reduzir a complexidade e simplificar o processo de tomada de decisão. Ou seja, os indivíduos podem vir a se beneficiar, de certo modo, do conhecimento codificado nas regras. Como regras são combinadas com sanções ao seu descumprimento, sendo lidadas pelos supervisores, aos seguidores, regras possuem dois aspectos: (1) de suporte, para reduzir complexidade e servir de guia; e (2) restritivo, por reduzir a liberdade de ação. A depender do tipo, da natureza e do contexto no qual a organização se encontre, um destes aspectos terá maior relevância do que o outro.

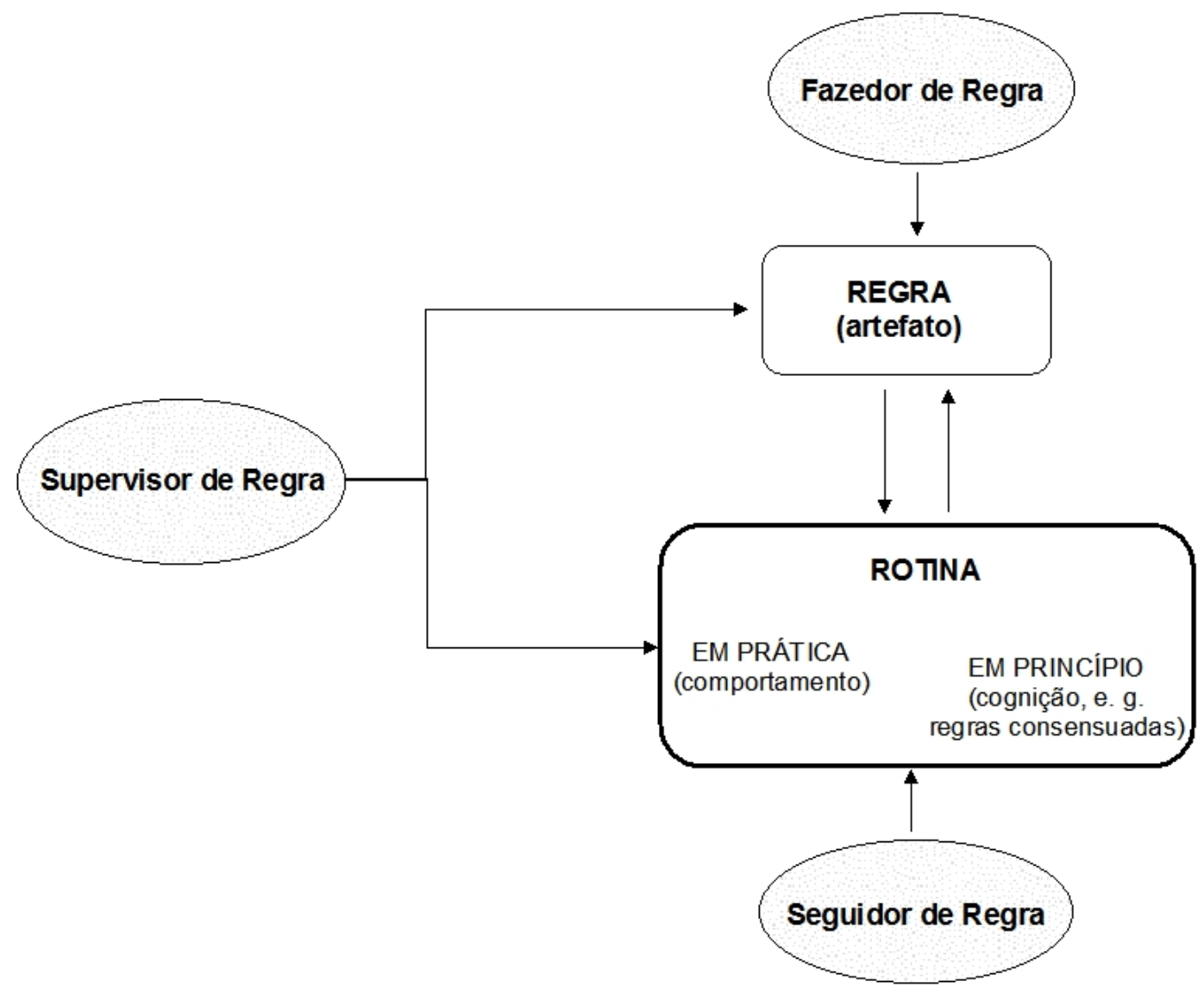

Figura 2 - Regras, rotina e relevantes stakeholders em Organizações Fonte: adaptado de Weichbrodt e Grote (2010, p. 22).

O modelo que contém a visão destes dois autores, quanto ao que vêm a ser regras e rotinas juntamente com a inclusão dos papéis a serem desempenhados por 
entidades, é apresentado a seguir. Weichbrodt e Grote (2010, p. 22) põem, na modelagem, o fazedor de regra como fortemente ligado à confecção da regra em si, pois esta, quando formalizada, é registrada em artefatos. O supervisor de regra exerce fator central ante as regras e as rotinas. Ele atua exercendo o seu papel de verificar se o rumo pretendido com as rotinas e regras está sendo atingido ao longo do tempo. Aos seguidores de regras, como a eles é determinado o que fazer, em suas ações é possível o cumprimento de regras. Portanto, estes se ligam, segundo os autores referenciados, mais fortemente às rotinas, particularmente, à rotina na prática, pois esta é o comportamento evidenciado. Porém, o conceito de regras e rotinas será tratado na próxima seção.

\section{Regras e Rotinas Organizacionais}

Como regras e rotinas são o cerne da teoria da estruturação social, elas são modificadas pela sua atuação prática, pelas ações das pessoas sobre suas determinações, no entanto cada uma possui conceituação diferente. Sobre regras, Grote et al. (2009) alegam que se trata de descrições formais, determinadas pela cúpula aos seus subordinados, de como proceder e interagir. Mas, para eles, regras não são iguais a rotinas em principio, nem em prática. Grote et al. (2009) tecem um paralelo ao conceito de aspectos performativos e ostensivos da rotina cunhados por Feldman e Pentland (2003).

Grote et al. (2009) dividem o conceito de rotina em dois aspectos: (1) rotina em princípio, conceito que é internalizado e performado em ações repetitivas; e (2) rotina na prática, que surge nas ações e que pode vir a modificar o seu princípio, em circunstâncias específicas. A analogia foi feita por Grote et al. (2009), no sentido de que eles enxergam a ostensividade da rotina como sendo mais próxima da rotina estática, em princípio, e a performatividade, com a rotina prática, que demanda inevitavelmente por improvisação e flexibilidade.

Portanto, as regras servem de estamento formal para performar a rotina na prática e de compartilhamento pelas pessoas, de como as rotinas devem ser compreendidas em princípio, de acordo com Grote et al. (2009). As regras também servem de base no delimitar do sistema que se quer gerenciar, e podem ser classificadas em três tipos: (1) de objetivos, onde se quer chegar; (2) de processo, acerca das decisões que devem ser tomadas no curso da ação; e (3) de ação, que descrevem as ações concretas a serem realizadas.

Grote et al. (2009) chamam a atenção sobre as regras de processo, que servem para processos flexíveis e estáveis. Estas devem considerar o desenvolvimento de "metas-rotinas", que são associadas aos mecanismos de coordenação, tais qual defendido por Mintzberg (2003). Estes mecanismos, segundo Grote et al. (2009), devem ser associados aos times e à efetividade organizacional. Sobre regras de objetivos, elas se associam às questões de planejamento de longo prazo, de cunho conceitual, não sendo tão específicas. Já as regras de ação descem ao nível da especificidade micro, do que deve ser feito nos detalhes mais específicos. A mudança nas regras em ambientes padronizados deve ocorrer por um processo incremental, segundo Grote et al. (2009), a fim de que seja exitoso. 
Dentre as três implicações de pesquisa feitas por Grote et al. (2009), ressalta-se a distinção que eles tecem acerca de "rotinas flexíveis" e o "uso flexível da rotina". O primeiro conceito é referente à liberdade que é incorporada pela tomada de decisão. O segundo, ligado ao uso da rotina, é referente à adaptação feita pelo "usuário" da regra sem necessariamente a regra em si explicitar esta possibilidade de adaptação. O uso flexível é, normalmente, anexado a possíveis maus usos e a possíveis sanções determinadas. Uma das considerações apontadas por Grote et al. (2009) reside na possibilidade de se reduzir a incerteza, por parte da organização, ou de se atribuir certa liberdade decisória aos trabalhadores, por meio do aumento/melhoria das competências individuais, para que o desempenho acerca de regras e rotinas seja o mais proveitoso possível.

Contudo, a abordagemdos aspectos que mais passam ao ponto de se modificar ou de quem vai executar o que e em qual momento é o cerne do trabalho de Weichbrodt e Grote (2010). Weichbrodt e Grote (2010, p. 2) afirmam serem regras e rotinas detentoras de um papel importante nas organizações: "Elas capacitam a coordenação entre indivíduos e unidades organizacionais, alinhando atividades e objetivos. Elas também podem ser vistas como provedoras de direcionamento e orientação para indivíduos". Assim como Grote et al. (2009), Weichbrodt e Grote (2010) alegam serem as regras e rotinas responsáveis pela redução de incerteza e ambiguidade no ambiente de trabalho, porém, elas podem restringir a liberdade de ação no trabalho das pessoas.

Weichbrodt e Grote (2010) atêm-se a distinguir, dentro da organização, as regras escritas das não escritas, juntamente com o comportamento que advém do comportamento oriundo das rotinas. Weichbrodt e Grote (2010) fazem distinção da rotina em princípio, em conceito, da prática como foi definida por Grote et al. (2009) e se utilizam do conceito de Pentland e Feldman (2005), que associam regras a artefatos, e rotinas ao comportamento coletivo. Dessa forma, Weichbrodt e Grote (2010) utilizam a denominação "regra" somente para se referir à algo formal, explicitado e escrito, o registro é um artefato para eles. Regras não escritas podem ser dividas em: (1) cultura ou normas consensuadas por um grupo, que, em seu princípio abstrato, passa a ser considerado como aspecto ostensivo da rotina; e (2) padrão de comportamento, que representa a prática evidenciada, o visualizado, portanto, os aspectos performativos, como foi defendido por Feldman e Pentland (2003).

Mas qual é a importância de se tratar regras, escritas e/ou rotinas, além de saber que elas servem de instrumento de poder e de mecanismos de coordenação, como apontados por Grote et al. (2009)? Para Weichbrodt e Grote (2010), regras são responsáveis por traduzir o abstrato, tal como eles citam os padrões de qualidade determinados pela série ISO 9001, em termos do entendimento coletivo. Este entendimento são regras e procedimentos organizacionais. Neste sentido, os ensinamentos de Csillag (1991, p. 66) alegam terem sido três movimentos (Just-inTime; Gerenciamento da Qualidade Total; e Teoria das Restrições) que modificaram as bases do gerenciamento industrial. A contribuição destas três áreas de estudo reside no visualizar o processo de melhoramento de forma constante. Essa forma de enxergar será tratada mais adiante, quando do enfocar no processo de melhoramento contínuo, que se concentra no ganho como medição ilimitada. 


\section{O Arcabouço Institucional no moldar de Regras e Rotinas}

A partir da teoria da estruturação social de Giddens (1984), que é dividida em visão de instituições, determinantes ao agir humano, e em estrutura, que se forma nas ações das pessoas, começa-se a demandar por ligações sobre estas duas visões: ações e instituições. Um trabalho que começa a apontar para esta ligação é o de Barley e Tolbert (1997). Estes autores desenvolveram um modelo recursivo entre a institucionalização e as ações. O reino institucional contempla um conjunto de regras e tipificações decorrentes de histórias e interações acumuladas, que identificam categorias de atores sociais e suas atividades, que lhe são próprias (BARLEY; TOLBERT, 1997, p. 95). Barley e Tolbert (1997), ao categorizarem vários níveis de atores sociais que são relevantes, abrem a possibilidade de encará-los como indivíduos, grupos, organizações ou até mesmo coletividades amplas.

O reino das ações é o arranjo atual de pessoas, recursos e eventos do fluxo social. Sobre este último, cabe saber como as ações tomadas pelas pessoas passam a afetar o outro reino. O que é recursivo aos dois reinos são os Scripts, que podem ser entendidos como atividades recorrentes e padrões de interação observáveis restritos a uma dada realidade. (BARLEY; TOLBERT, 1997, p. 97). Portanto, as instituições compreendem o compartilhar de regras, e estas são compartilhadas e performadas nas ações, o que pode ser visualizado no modelo de Barley e Tolbert (1997, p. 100) transcrito a seguir. Os dois reinos são conectados por linhas verticais, que representam as restrições institucionais sobre as ações, e diagonais, que são resultado das ações que modificam e/ou mantêm o instituído. (BARLEY; TOLBERT, 1997, p. 99).

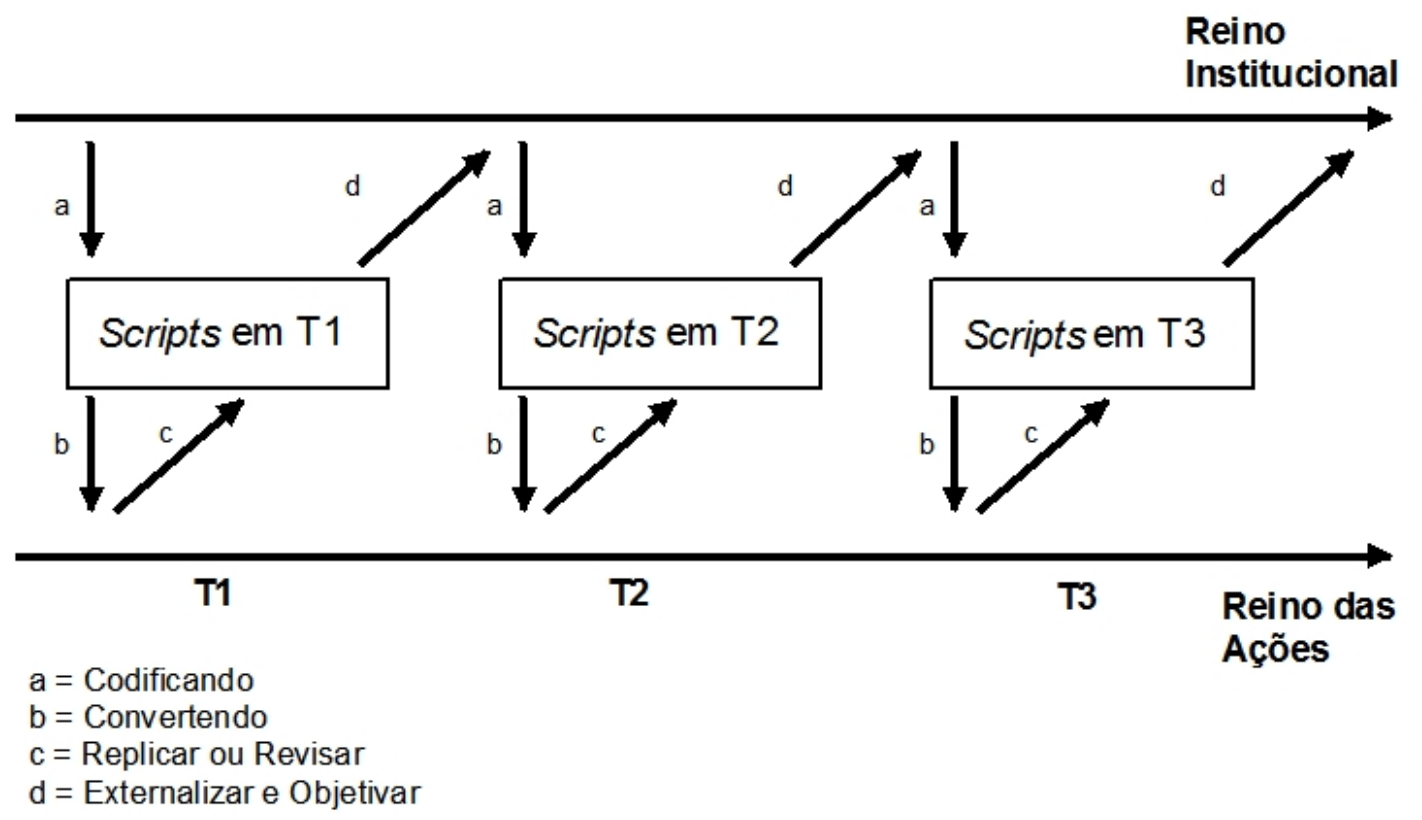

Figura 3 - Um Modelo Sequencial de Institucionalização

Fonte: adaptado de Barley e Tolbert (1997, p. 100). 
O primeiro momento idealizado no modelo, que é uma representação do que ocorre ao longo do tempo, trata-se da codificação dos princípios institucionais em scripts específicos. Normalmente, a atuação do "codificar" demanda o processo de socialização e internalização pelos indivíduos de regras e interpretação de comportamentos coletivos. O segundo momento é a conversão, que pode não ser consciente completamente, porém a consciência se faz importante ao modificar instituições. Converter é referente ao codificar pelos atores do princípio institucional. Contudo, podem ser observados elementos tácitos. O terceiro momento posto no modelo de Barley e Tolbert (1997) sai dos scripts e adentra no reino das ações, no qual as pessoas revisam ou replicam os scripts passados pelas ações. Se ocorrem alterações, elas são fruto das ações conjuntas. Por fim, o quarto momento é referente ao desassociar de ações e atores específicos, passando à aquisição de normas, que se denomina externalizar e objetivar algo estabelecido socialmente ao reino institucional.

O modelo desenvolvido por Barley e Tolbert (1997) é relevante no que tange à possibilidade de dinamizar as teorias propostas por Giddens (1984), em termos de passar algo institucionalizado a ser modificado pelas ações humanas. Nesse sentido, as mudanças institucionais passam a ser visualizadas e comparadas, como era e como passa a ser, quando passa-se a analisar os diferentes instantes dos scripts denominados por T1, T2 e T3, como visualizados na FIG 3.

Posteriormente a este trabalho, Burns e Scapens (2000) estudaram a mudança da gestão contábil em organizações como um processo sobre regras e rotinas que são compartilhadas por dentro da organização e passam a ser diretrizes externas. As mudanças que acontecem no processo de gestão contábil são fruto das modificações que ocorrem nas rotinas organizacionais, em suas práticas, que passam a ser potencialmente institucionalizadas (BURNS; SCAPENS, 2000, p. 5).

O trabalho de Burns e Scapens (2000) assemelha-se, em alguns aspectos, ao de Barley e Tolbert (1997) na questão de se ver os dois reinos, o institucional e o das ações, como que em paralelo e algo sendo performado em meio aos dois. No entanto, para o trabalho mais recente, a noção de script passa a ser encarada como uma relação entre regras e rotinas. Para Burns e Scapens (2000, p. 6), regras passam a ser vistas como o modo formal no qual "as coisas devem ser feitas". Regras são necessárias para fornecer coerência nas relações grupais e individuais, portanto, pode-se dizer que elas podem ser presentes em informação contida em manuais, por exemplo, como os de qualidade. A repetição da regra gera 0 comportamento alicerçado em conhecimento tácito, de acordo com Burns e Scapens (2000).

Burns e Scapens (2000) tratam as rotinas como sendo representativas do comportamento baseado em regras. Rotinas representam os comportamentos do grupo, muitos deles sendo desenvolvidos sobre algum padrão formal, portanto elas podem ser definidas como "as coisas que são atualmente feitas" (BURNS; SCAPENS, 2000, p. 6). Nesse sentido, ressalta-se a distinção de hábito e rotina que é feita por estes autores. Para eles, hábito é o comportamento evidenciado e realizado por pessoas, de forma singular. O comportamento que é compartilhado por indivíduos e grupos passa a ser denominado rotina (BURNS; SCAPENS, p.6). Ou seja, "regras são estabelecidas e, na sua implementação, rotinas irão emergir" (BURNS; SCAPENS, 2000, p. 7). 


\section{Reino Institucional}

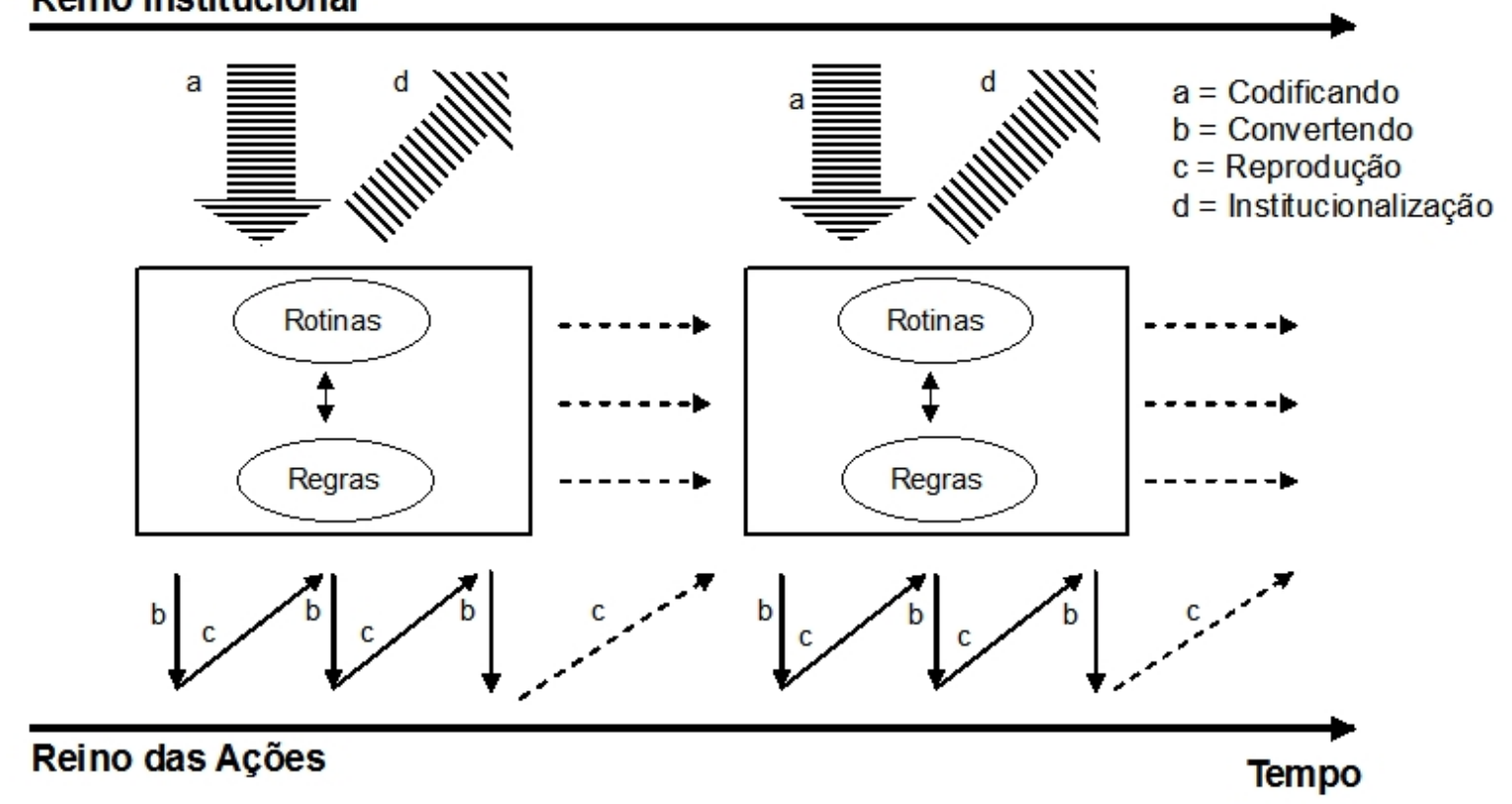

Figura 4 - O processo de Institucionalização

Fonte: adaptado de Burns e Scapens (2000, p. 9).

Como pode ser observado na FIG 4, o modelo de Burns e Scapens (2000) assemelha-se muito ao de Barley e Tolbert (1997). Essencialmente, a semelhança ocorre na relação agência, ligada a ações humanas, e estrutura, à institucionalização que é desprovida de intencionalidade individual, alicerçada no entendimento e estoque de conhecimento coletivo. Contudo, há algumas nuances que merecem ser destacadas.

Primeiramente, as setas que partem e que retornam ao reino institucional são mais destacadas, mais grossas do que as estabelecidas no trabalho de 1997. Essa diferença ocorre pelo fato de Burns e Scapens (2000, p. 7) acreditarem que as instituições estão nos atores, na forma como o "caminho/jeito das coisas são", não sendo associadas a um determinado contexto em particular, mas sendo aplicadas a vários. Por serem mais difíceis de mudar e mais determinantes ao estabelecimento de regras e rotinas, estes "caminhos" são menos frequentes e mais fortes.

Em segundo lugar, em contraposição ao que ocorre ao reino institucional, o reino das ações possui certa frequência sobre as ações que estão sendo executadas. Isso ocorre devido ao fato de que é necessário, ao processo de socialização e internalização dos indivíduos, certa repetitividade das ações para que a regra e a rotina sejam internalizadas e conhecidas. Após este conhecimento, a reflexão crítica 
passa a acontecer, e a mudança do que está sendo feito passa a ocorrer mais fortemente. Nesse processo, como bem destacaram Burns e Scapens (2000), rotinas emergentes, que passam amplamente a ser aceitas na organização, tornamse uma forma inquestionável de controle gerencial. Se há controle, pode-se dizer que são institucionalizadas.

Como terceira questão modificada por Burns e Scapens (2000), se comparada a Barley e Tolbert (1997), evidencia-se a denominação de que scripts passam a ser denominados de regras e rotinas, que surgem e se alteram ao longo do tempo. Sobre o surgimento, é pertinente dizer que este é de difícil predição, porém é dependente do caminho, no qual rotinas e instituições existentes moldam a seleção e implementação de novas regras e rotinas (BURNS; SCAPENS, 2000, p. 12).

Para haver mudança institucional, o entendimento da continuidade e estabilidade se faz presente tal qual um gene, como foi tratado por Nelson e Winter (2005), segundo Burns e Scapens (2000). Estabilidade se faz importante para se compreender a mudança, pois elas não são independentes do que se fazia antes. Estabilidade e mudança são parte de um mesmo processo, de acordo com Burns e Scapens (2000), tal qual foi também tratado por Feldman (2000). A dicotomia é percebida e tratada, ao contexto da mudança da gestão contábil, por Burns e Scapens (2000), como envolvendo três possibilidades de aprofundamento: (1) mudança formal e informal; (2) mudança evolucionária e revolucionária; e (3) mudança regressiva e progressiva.

A mudança formal normalmente é associada a uma inserção de uma nova regra pensada e planejada. $O$ seu êxito, em sua implementação, requer novas possibilidades de pensar das pessoas. Já a informal ocorre em adaptações de cunho mais tácito, sobre rotinas que são performadas pelas pessoas. Caso o processo de mudança informal ocorra mais lentamente do que a formalizada, poderá vir a acontecer ansiedade e resistência das pessoas, o que pode comprometer a implementação da "novidade". As mudanças podem advir quando da conversão e da reprodução, que ocorrem do e para o reino das ações para e das regras e rotinas (BURNS; SCAPENS, 2000).

Mudança revolucionária envolve uma ruptura nas regras, rotinas e instituições que são consideradas pelas pessoas. A evolucionária considera a mudança de modo incremental, normalmente associada à intencionalidade e à formalidade da mudança, na qual as quebras nas rotinas e instituições que são trabalhadas ocorrem de modo mais ameno. Por fim, a dicotomia da mudança regressiva e progressiva, como tratada por Burns e Scapens (2000), consiste na associação da regressiva ao comportamento que reforça o cerimonial, que emerge de um sistema de valor, que preserva a estrutura de poder atual, portanto restringe a mudança institucional. Já a mudança progressiva desconsidera o comportamento cerimonial em prol do instrumental. Este é emergente de um sistema de valor que considera a aplicação do melhor conhecimento e tecnologia disponíveis para a solução de problemas. 


\section{O Processo de Enfoque e a Estruturação Social: contraposição e proposição de novo visualizar acadêmico}

O Processo de Enfoque está contido no "Mundo do Ganho", onde as suas variáveis são dependentes e o elo mais fraco é a restrição a ser trabalhada (CSILLAG, 1991, p. 67). A mudança a ser tratada, tendo por base este modelo, é enfocar nas restrições, acima de tudo, tendo por base o princípio da corrente, no qual os processos estão interligados e, para haver ganho, deve-se atentar ao elo mais fraco, reforçando-o. O reforço conferido a este elo acarretará melhoria a todo o sistema, direcionando os recursos ao atingir melhor as metas da organização (CSILLAG, 1991; GOLDRATT; COX, 2014).

Como se trata de mudança, o pressuposto adotado em grande parte dos processos de mudança, inclusive seguidos pela teoria da estruturação social, é o de que a transformação organizacional pode ser administrada, isto é, conduzida segundo as intenções e expectativas dos líderes formais. O papel do líder é mais do que requisitado. Assim, insere-se à discussão o papel do fazedor de regras como um dos fatores-chave de êxito à implementação do "mundo do ganho" na organização. Ele é que, em consonância com Weichbrodt e Grote (2010), detém o poder. Ao lidar com mudança de mentalidade, então o poder pode advir de entidades externas, por mecanismos isomórficos, tais quais o coercitivo, o normativo ou o mimético. Esta absorção será obtida de acordo com a capacidade que as pessoas tenham, capitalizadas pelo fazedor de regras, no poder inerente que ele detenha, como o que o dia a dia interno das regras e rotinas, em absorver o que vem de fora, do mundo exterior, por capacidades absortivas (COHEN; LEVINTHAL, 1990) esse novo conhecimento.

Continuando o elo comparativo, a Teoria das Restrições, como apontado por Csillag (1991), remete mais a questões de planejamento, de mudança de mentalidade, de valores que os gerentes possuem. Diante de tal assertiva, a questão da formalização, intencionalidade, evolução e progressividade da mudança institucionalizada (BURNS; SCAPENS, 2000), passa a ser mais fortemente considerada em planejamento. Ou seja, a adesão do reino institucional à nova formatação diante as possibilidades de gerenciamento deve ser mais fortemente considerada.

Embasando-se em Barley e Tolbert (1997), na sua noção de Scripts, que são definidos como sendo atividades e padrão de interação recorrentes observáveis em uma dada realidade particular (BARLEY; TOLBERT, 1997, p. 97), pode-se supor que as instituições compreendem o compartilhar de regras, e estas são performadas nas ações. O modelo desenvolvido por Barley e Tolbert (1997) é relevante no que tange à possibilidade de dinamizar as teorias propostas por Giddens (1994), em termos de passar algo institucionalizado a ser modificado pelas ações humanas. Nesse sentido, as mudanças institucionais passam a ser visualizadas e comparadas, como era e como passa a ser a nova mudança, e como a modificação estabelecida passa o olhar aos diferentes instantes dos scripts.

Os Scripts são o que, analogamente, compara-se com as cinco etapas do processo de enfoque apontadas por Csillag (1991). Como os Scripts são os "instantes" que passam a outras ações, são eles que resultam em "regras e rotinas" para Burns e Scapens (2000). Infere-se assim que o processo de enfoque é equivalente a regras

RELUNA, Belo Horizonte - MG, Brasil, v.2Z, n.I, p.2I-4D, Jan. - Mar. 2017 - ISSN 2174-8834 
e rotinas, sejam em princípio, no conceito da restrição que se queira atribuir, física ou não-física, como no processo da atuação na prática, sobre o melhoramento contínuo da restrição.

As etapas do Processo de Enfoque, de acordo com Csillag (1991) e Goldratt e Cox (2014) são: (1) identificar as restrições; (2) conseguir o aproveitamento máximo da restrição; (3) subordinar tudo o que for possível às restrições identificadas; (4) Reduzir ou suprimir a(s) restrição (ões); e (5) Sempre que uma restrição é quebrada, deve-se retornar ao primeiro passo. Cada etapa possui comparação com os modelos apresentados nas FIGs 3 e 4, anteriormente relatadas.

Csillag (1991) define como primeiro passo a identificação das restrições, sendo que estas são remetidas ao (1) ambiente interno, que retoma o âmbito das ações, ou o (2) externo, ao reino institucional, da modelagem de Burns e Scapens (2000) e Barley e Tolbert (1997). Portanto, a restrição, interna, inerente a um equipamento, ou externa, presente no mercado, demanda tempo para ser trabalhada e eliminada.

O processo de identificação remete ao transpor de algo presente nas instituições de uma mentalidade, de uma forma de agir possível e vista por uma determinada sociedade. Portanto, esta circunscrição relaciona-se ao ponto "a", codificando, presente nas FIGs 3 e 4 . Onde são vistos os aspectos que são restritivos diante de um modelo institucionalmente aceito, a organização tenta assimilar suas melhores práticas. Caso seja tecido um paralelo com os três tipos de regras de Weichbrodt e Grote (2010), o enfoque é decorrente das regras de objetivos, haja vista o fato de se estar, em um primeiro momento, identificando a restrição para se trabalhá-la.

Os pontos 2 a 4 das etapas do modelo de enfoque de Csillag (1991) podem ser comparados aos pontos "b" e "c" da modelagem das FIGs 3 e 4. Porém, o confronto puro e simples destas etapas não pode ser feito sem ser considerada a atuação de "agentes", que estão atuando no presente, com base no que se passou, tentando aprimorar seu futuro (EMIRBAYER; MISCHE, 1998). Este que é associado ao modo de se ver o negócio pela perspectiva do mundo do ganho. Nesse sentido, o papel do agente pode ser visualizado como o de fazedor, supervisor e seguidor de regras de Weichbrodt e Grote (2010).

Assim, em contraposição dos dois modelos, em sua comparação, sugere-se a seguinte primeira proposição: Proposição 1 - A identificação da restrição será facilitada quando a delimitação da regra, do que se quer atingir,a meta, é estabelecida respeitando as determinações do ambiente institucional, em conjunto com as habilidades e comportamentos das pessoas.

Quando parte-se à segunda etapa, da exploração da restrição do sistema, passa-se a ser considerado, mais fortemente, o papel do fazedor de regra no determinar do elo mais fraco. A regra exigida é a de processo (GROTE et al., 2009), que começa a explorar alternativas de otimização da restrição ao sistema, sem que detalhes da tarefa específica sejam feitos. O foco recai sobre o aproveitamento máximo da restrição (CSILLAG, 1991; GOLDRATT; COX, 2014). Sendo assim, surge a segunda proposição: Proposição 2 - Definida a meta, no explorar da restrição, o fazedor de regra deve se focar apenas no processo produtivo em si, sem deixar de se atentar aos desígnios institucionais, conjuntamente com os arranjos comportamentais rotineiros da organização. 
Na etapa três, de subordinação do sistema à restrição determinada, encontra-se, também, a atuação do fazedor de regra. Porém, como se trata de reagrupar ordenadamente em termos de prioridades sobre a restrição encontrada, diante dos recursos presentes na organização, o supervisor de regra passa a ser fundamental no perceber se a subordinação de recursos está ocorrendo em conformidade com a restrição estabelecida para otimizar. Nesta etapa, o bom performar das rotinas estabelecidas aos seguidores de regras cumpre função relevante, sendo assim este papel de Weichbrodt e Grote (2010) não pode ser preterido.

Portanto, é na terceira etapa que os supervisores e seguidores de regras passam a ser mais requisitados e atuantes no processo de enfoque. Assim, surge a terceira proposição: Proposição 3 - Estabelecida a meta, as regras de objetivos e de processos pelos fazedores, deve-se atentar à performance da rotina na prática, que fica a cargo do supervisor de regra sobre as regras de ação, que devem respeitar as ações concretas de subordinação do sistema à(s) restrição(ões) identificadas.

Também, o supervisor de regras é importante para o êxito da próxima etapa, que é da supressão ou redução da restrição. Ele se faz relevante no momento em que passa a gerir o que deve ser aplicado, ao limite da eliminação da restrição, que foi, na primeira etapa, identificada. Será a pessoa/entidade que identificará o ponto no qual o acréscimo de recurso, que seja restrição, não melhorar o sistema. Ao considerar a modelagem de Weichbrodt e Grote (2010), posta na FIG 2, percebe-se que o superviso de regra é elo central no entendimento da regra, para verificar como ela está sendo compreendida e trabalhada na prática. Assim, surge a quarta proposição, fruto da contraposição teórica trabalhada: Proposição 4 - O supervisor de regras é o elo principal do processo de enfoque, pois ele é o verdadeiro gestor dos recursos restritivos ao sistema e o que compreende a regra, a meta, e busca verificar se está ocorrendo na prática.

Por fim, o próximo passo da etapa de enfoque, de Goldratt e Cox (2014), considerado por Csillag (1991), é o retorno ao primeiro passo. Nesse retorno, uma nova determinação, uma nova ordem interna ao sistema produtivo, passa a ser vista, e o ponto "d" da FIG 4, em particular, que é o da institucionalização, passa a ser evidenciado. Trata-se do processo de se retomar do reino institucional novas determinações para lidar com novas restrições que são evidenciadas. Nesse sentido, surge a quinta proposição: Proposição 5 - Na eliminação de uma restrição a um determinado sistema produtivo, o ensinamento sobre parte do meio ambiente institucional passa a ser nova restrição a ser considerada na captação de "códigos" institucionais.

O maior aprendizado, que se pode obter com a contraposição teórica proposta, é referente a quem faz e a quem determina o que fazer, em termos de melhorar continuamente o sistema. Estas pessoas devem ter capacidades de aprender e questionar as limitações do sistema em que estejam inseridas. Elas devem possuir capacidade de aprendizado e ser absortivas (COHEN; LEVINTHAL, 1990). No entanto, uma questão que salta aos olhos é o fato de que os modelos das Teorias das Restrições, como as etapas de enfoque, são associadas e voltadas mais para o entendimento das capacidades, da teoria da RBV, que se foca mais no que os recursos podem ser melhor aplicados.

Não obstante, quando se considera a estruturação social de Giddens (1984), como tratada por Burns e Scapens (2000), particularmente, na questão de rotinas e regras, 
o foco deve ser no que as pessoas podem vir a executar para melhor produzir. Nesse sentido, insere-se à discussão a noção do ciclo de recursos proposto por Feldman (2004), com o qual, a partir da atuação das pessoas com seus esquemas, associadas a rotinas, pode-se desenvolver um melhor arcabouço de recursos para lidar com as mudanças e dificuldades encontradas pela organização. Como consequência, espera-se contribuir com o melhor tratamento dos recursos que sejam restrição ao sistema, considerando a noção de "esquemas" de Feldman (2004).

Essa discussão de rotinas, presente em Feldman (2000; 2003; 2004) e em Becker (2004; 2005a; 2005b), remete ao entendimento de ela ser comportamento coletivo. O comportamento por si só pode ser considerado como uma restrição não-física (MARQUES; CIA, 1998). Comportamento que deve ser voltado para a melhoria contínua, como bem destacou Csillag (1991). Contudo, quem deve fazer o que em termos de entendimento de regras e rotinas? Uma forma de contraposição teórica foi esta tratada por este presente trabalho, que tem por proposição maior o desenvolvimento de junção teórica entre a Teoria das Restrições e os trabalhos que têm a rotina por base. Porém, a proposta de confluência e entendimento está no seu início.

\section{Referências}

BARLEY, S. R.; TOLBERT, P. S. Institutionalization and Structuration: Studying the links between action and institution. Organization Studies, v. 18, issue 1, p. 93-117, 1997.

BARNEY, J. B. Firm resources and sustained competitive advantage. Journal of Management. v. 17, n. 1, p. 99-120, 1991.

BECKER, M. C. A framework for applying organizational routines in empirical research: linking antecedents, characteristics and performance outcomes of recurrent interaction patterns. Industrial and Corporate Change, v. 14, n. 5, p. 817-846, September 2005.

BECKER, M. C. Organizational routines: a review of the literature. Industrial and Corporate Change, v. 13, n. 4, p. 643-677, 2004.

BECKER, M. C. The concept of routines: some clarifications. Cambridge Journal of Economics, v. 29, n. 2, p. 249-262, 2005.

BURNS, J.; SCAPENS, R. W. Conceptualizing management accounting change: an institutional framework. Management Accounting Research, v. 11, p. 3-25, 2000.

COHEN, W. M.; LEVINTHAL, D. A. Absorptive Capacity: a new perspective on learning and innovation. Administrative Science Quarterly, v. 35. p. 128-152, 1990.

CSILLAG, J. M. O Significado do Mundo do Ganho. Revista de Administração de Empresas, (São Paulo), v. 31, n. 2, p. 61-68, 1991.

DiMAGGIO, P.; POWELL, W. W. The Iron Cage Revisited: Institutional Isomorphism and Collective Reality in Organizational Fields, American Sociological Review, v. 48, n. 2, p. 147-160, 1983. 
EMIRBAYER, M.; MISCHE, A. What is Agency? The American Journal of Sociology, v. 103, n. 4, p. 962-1023, January, 1998.

FELDMAN, M. S. A Performative perspective on stability and change in organizational routines. Industrial and Corporate Change. v. 12, n. 4, p. 727-752, 2003.

FELDMAN, M. S. Organizational Routines as a Source of Continuous Change. Organization Science. v. 11, n. 6, p. 611-629, Nov-Dec, 2000.

FELDMAN, M. S. Resources in Emerging Structures and Processes of Change. Organization Science, v. 15, n. 3, p. 295-309, May-June, 2004.

FELDMAN, M. S.; PENTLAND, B. T. Reconceptualizing Organizational Routines as a Source of Flexibility and Change. Administrative Science Quarterly. v. 48, n. 1, p. 94118, Mar, 2003.

GIDDENS, A. The Constitution of society: outline of the theory of structuration. Cambridge/UK: Polity Press, 1984.

GOLDRATT, E. M.; COX, J. A meta: Um processo de aprimoramento contínuo. 2. ed. São Paulo: Nobel, 2014.

GROTE, G.; WEICHBRODT, J. C.; GÜNTER, H.; ZALA-MEZÖ, E.; KÜNZLE, B. Coordination inhight-risk organizations: the need for flexible routines. Cognition, Technology and Work, v. 11, issue1, p. 17-27, Jan, 2009.

MACHADO-DA-SILVA, C., FONSECA, V.; FERNANDES, B. R. Mudança e Estratégia nas Organizações: perspectivas cognitivas e institucional. In: VIEIRA, M. M. F.; OLIVEIRA, L. M. B. Administração Contemporânea, perspectivas estratégicas. São Paulo: Atlas, 1999.

MARQUES, J. A. V. C.; CIA, J. N. S. Teoria das Restrições e Contabilidade Gerencial: Interligando Contabilidade e Produção. Revista de Administração de Empresas, (São Paulo) v. 38, n. 3, p. 34-46.

MINTZBERG, H. Criando Organizações Eficazes: estruturas em cinco configurações. 2. ed. São Paulo: Atlas, 2003.

MOTTA, F. C. P.; VASCONCELOS, I. F. G. Teoria geral da Administração. 2. ed. São Paulo: Pioneira Thomson, 2005.

NELSON, R. R.; WINTER, S. G. Uma teoria evolucionária da mudança econômica. Campinas, SP: Editora da UNICAMP, 2005.

PENG, D. X.; SCHROEDER, R. G.; SHAH, R. Linking routines to operations capabilities: A new perspective. Journal of Operations Management. v. 26, p. 730748, 2008.

PENTLAND, B. T.; FELDMAN, M. S. Designing routines: On the folly of designing artifacts, while hoping for patterns of action. Information and Organization, v. 18, p. 235-250, 2008.

SCOTT, W. R. Institutions and organizations. Thousand Oaks: Sage, 1995 Capítulos 1, 2, 3 e 4.

SLACK, N.; CHAMBERS, S.; JOHNSTON, R. Administração da Produção. 3. ed. São Paulo: Atlas, 2009. 
WEICHBRODT, J.; GROTE, G. Rules and Routines in Organizations: a review and extension. In: Fourth International Conference on Organizational Routines. Nice/France, June/2010. Proceeding... p. 1-35, June/2010.

WHITTINGTON, R. Putting Giddens into action: Social Systems and Managerial Agency. Journal of Management Studies. v. 29, issue 6, p. 693-712, 1992. 